\title{
Histomorfometria, apoptose e proliferação celular em neoplasias intraepiteliais do colo uterino
}

\author{
Histomorphometry, apoptosis and cell proliferation in cervical intraepithelial neoplasia
}

Rodrigo Tadeu de Puy e Souza'; Lorena Barcala Reis²; Carlos Alberto Ramos ${ }^{3}$; Antonio Francisco de Souza ${ }^{4}$; Gustavo Henrique de Puy e Souza5; Núbia Braga Pereira6; Luciana Moro7; Anilton Cesar Vasconcelos ${ }^{8}$

\begin{abstract}
unitermos
resumo

Patologia cervical

Introdução: As displasias do colo uterino são precursoras do carcinoma de células escamosas. Mutações

Neoplasia intraepitelial induzidas por carcinógenos correlacionam-se com alterações proliferativas. O acúmulo dessas mutações cervical e o descontrole da homeostase genômica permitem mudanças na expressão de determinados genes e geram desequilíbrios na proliferação celular e na apoptose. Marcadores imuno-histoquímicos de proliferação

Proliferação celular celular, de apoptose e de sobrevivência celular em lesões intraepiteliais cervicais ainda necessitam de estudo morfométricos para definir seus papéis na evolução das displasias ao carcinoma invasivo. Objetivos: Para Apoptose melhor entender os processos de proliferação celular, apoptose e renovação epitelial nessas lesões, foram realizadas histomorfometria para mitose e apoptose e reações imuno-histoquímicas das proteínas Bax, Bcl-2 e Ki-67 (reatividade, localização e intensidade) em biópsias cervicais. Métodos: As amostras foram divididas em quatro grupos: 1 . cervicite $(n=20) ; 2$. displasia leve $(n=20) ; 3$. displasia moderada $(n=20) ; 4$. displasia acentuada $(n=20)$. Resultados: Foram verificadas intensa proliferação celular e apoptose nas lesões de alto grau e ampla, intensa e difusa imunomarcação para Ki-67 e Bax. Esses achados foram encontrados de maneira discreta ou nula nos grupos cervicite e displasia leve. A marcação para Bcl-2 foi mais intensa nas lesões de alto grau, tendo sido discreta nas demais. A ampla marcação imuno-histoquímica de Ki-67 e Bax é sugestiva de elevado grau de renovação celular, o qual também é sustentado pela histomorfometria. A expressão do Bcl-2 aumenta com a gravidade da displasia. Conclusão: Esses achados indicam que o processo pré-neoplásico é dinâmico, com apoptose e mitose ocorrendo concomitantemente.
\end{abstract}

abstract

Introduction: Cervical dysplasias are precursor to squamous cell carcinoma of the uterine cervix. Carcinogen induced mutations correlate with proliferative alterations. Accumulation of such mutations and unbalance of genomic homeostasis induce changes in certain genes as well as affect cell proliferation and apoptosis. Immunohistochemical markers of cellular proliferation, apoptosis and cell survival in cervical intraepithelial lesions still require morphometric studies in order to define their role in the development of dysplasias caused by invasive carcinoma. Objectives: In order to better understand the processes of cellular proliferation, apoptosis and epithelial turn over in such precursory lesions, histomorphometric evaluation for mitosis and apoptosis as well as immunohistochemical reactions for Bax, BCl-2 and Ki-67 proteins (reactivity, localization and intensity) were carried out in cervical biopsies. Methods: Samples were split into four groups: 1. cervicitis $(n=20)$; 2. light dysplasia $(\mathrm{n}=20) ; 3$. moderate dysplasia $(\mathrm{n}=20) ; 4$. severe dysplasia $(\mathrm{n}=20)$. Results: Intense proliferation and apoptosis were observed in lesions with high, extensive, intense, and diffuse Ki-67 and Bax immunolabeling. Proliferation and apoptosis were mild or null in groups 1 and 2. BCl-2 immunolabeling was more intense in high degree lesions and mild in the other groups. Extensive Ki-67 and Bax immunolabeling suggests an increased cellular turn over, which was also corroborated by histomorphometry. The more severe the dysplasia is the higher BCl-2 expression. Conclusion: These data indicate that the pre-neoplastic process is dynamic and is concomitant with apoptosis and mitosis. key words

Cervical pathology

Cervical intraepithelial neoplasia

Cell proliferation

Apoptosis

Ki-67

$B c /-2$

Bax

1. Mestre em Patologia pela Universidade Federal de Minas Cerais (UFMG); médico patologista.

2. Médica.

3. Médico anatomopatologista.

4. Doutor em Patologia; professor aposentado do Instituto de Ciências Biológicas (ICB) da UFMC.

5. Médico patologista; residente em Anatomia Patológica no Hospital das Clínicas (HC) da UFMG.

6. Mestra em Patologia pela UFMG; doutoranda em Patologia pela UFMG.

7. Doutora em Patologia; professora associada do ICB/UFMC.

8. PhD em Patologia Comparada; professor titular do ICB/UFMG.

Suporte financeiro: Fundação de Amparo à Pesquisa do Estado de Minas Cerais (FAPEMIC) e Conselho Nacional de Desenvolvimento Científico e Tecnológico (CNPq). 


\section{Introdução}

O Instituto Nacional de Câncer (INCA) estimou para 2010 o aparecimento de 18.430 novos casos de câncer de colo do útero no Brasil, com risco relativo de 18 casos/100 mil habitantes, com 4.812 óbitos. Destaca-se ainda o longo curso de história natural da doença (média de 15 anos entre a infecção viral e a neoplasia invasiva) e a sobrevida média entre $49 \%$ e $69 \%$ em cinco anos ${ }^{(5)}$.

O fator de risco mais significativo na etiologia desse tipo de câncer é a infecção pelas amostras virais oncogênicas do papilomavírus humano (HPV), que promovem lesões pré-neoplásicas, as neoplasias intraepiteliais do colo uterino $^{(6,9,37)}$.

Mutações causadas pelos carcinógenos correlacionam-se com alterações proliferativas. O acúmulo dessas mutações ocasiona o descontrole da homeostase genômica, permitindo a superexpressão ou subexpressão de determinados genes, gerando desequilíbrios no crescimento celular, na apoptose e na senescência ${ }^{(13,28)}$. Assim, o processo de apoptose parece ter uma relação de proximidade com o prognóstico para o paciente portador dessas neoplasias intraepiteliais do colo uterino.

Testes imuno-histoquímicos podem melhorar o reconhecimento e a classificação das lesões precursoras. Adicionalmente, podem favorecer o diagnóstico e a classificação de vários tipos de tumores malignos que ocorrem nesses sítios $^{(31)}$.

Marcadores de proliferação celular por imuno-histoquímica, como o Ki-67, têm sido testados em diversas neoplasias ${ }^{(15)}$. Entretanto, necessitam de estudo com maior número de casos para definir seus papéis na evolução da neoplasia intraepitelial cervical (NIC) .

Bax pertence à família de proteínas que partilham homologia semelhante à oncoproteína $\mathrm{BCl}-2$. As proteínas relacionadas com $\mathrm{BCl}-2$ estão envolvidas na regulação da apoptose, atuando como promotores ou supressores da morte celular. A superexpressão do Bax leva à promoção da morte celular. Foi proposto que a expressão relativa de diferentes proteínas da família $\mathrm{Bcl}-2$ controla a sensibilidade das células diante de um estímulo apoptótico ${ }^{(8)}$.

\section{Material e métodos}

Foram selecionadas 80 amostras, distribuídas em quatro grupos ( $n=20)$, sendo um não afetado (cervicite) e três lesões precursoras (NIC 1, NIC 2, NIC 3/carcinoma in situ).
Todos os procedimentos do protocolo experimental foram aprovados pelo Comitê de Ética em Pesquisa da Universidade Federal de Minas Gerais (UFMG) (ETIC 606/08, de 20 de fevereiro de 2009).

Capturaram-se todas as imagens disponíveis representativas das lesões nos cortes das biópsias, utilizando-se objetiva de 40x em câmera digital acoplada a um computador e usando o programa Media Cybernetics Image-Pro Plus versão 4.5. Os parâmetros morfométricos foram: número de apoptoses (total e nas camadas superior e inferior), número de mitoses (total e nas camadas superior e inferior) e células em interfase.

O índice apoptótico (número de células apoptóticas / número total $\times 100$ ) e o mitótico (número de células em metáfise, anáfase e telófase / número total $\times 100$ ) foram obtidos com base na morfologia. Cortes histológicos de $4 \mu \mathrm{m}$ foram montados em lâminas silanizadas e processados para imuno-histoquímica utilizando-se os anticorpos Mib-1 (clone DVB-2, Dakocytomation, Carpinteria, Ca, Monoclonal, Camundongo, 1:1), Bax (clone 2D2, Invitrogen, Camundongo, Monoclonal, 1:200) e Bcl-2 (Clone 124, Dakocytomation, Carpinteria, $\mathrm{Ca}$, Camundongo, Monoclonal, 1:100). O índice apoptótico (número de células apoptóticas / número total de células $\times 100$ ) foi obtido das observações de um único indivíduo, considerando como apoptóticas as células que apresentavam pelo menos três das seguintes características morfológicas peculiares ao processo, conforme Kerr et al. ${ }^{(15)}$ : 1. anoiquia (presença de halo claro perinuclear); 2. condensação do citoplasma; 3. condensação nuclear (às vezes com aspecto de crescentes); 4. fragmentação nuclear; 5 . fragmentação celular (corpos apoptóticos).

As etapas da reação imuno-histoquímica foram:

- desparafinização - em estufa, a $60^{\circ} \mathrm{C}$, por 15 minutos, e imersas em xilol, por 10 minutos (diafanização);

- reidratação pela passagem de álcool absoluto para água deionizada por três vezes;

- recuperação antigênica com tampão Diva Tris (0,05 mol/l, Tris-HCL, pH 6, 0,015 mol// Sodium azide e Carrier protein) e panela de vapor, a $90^{\circ} \mathrm{C}$, por 20 minutos;

- bloqueio da peroxidase endógena com $\mathrm{H}_{2} \mathrm{O}_{2}$ 10 volumes, por 5 minutos, e repetição por mais duas vezes;

- aplicação do Background Sniper por 10 minutos e lavagem com tampão Tris; 
- uso do anticorpo primário (Mib-1 pronto para uso; Bax na diluição 1:200; Bcl-2 na diluição 1:100) por 20 minutos;

- revelação estreptavidina-biotina (sistema revelador: Biocare's Star Trek Universal HRP detection) - com o Trekkie Universal Link (anticorpo secundário) por 20 minutos;

- enxágue com tampão Tris;

- revelação com o cromógeno Betazoid DAB Chromogen Kit e repouso por até 5 minutos;

- contracoloração com hematoxilina de Mayer's por 2 minutos, três banhos de álcool absoluto e três banhos de xilol, posteriormente com água corrente;

- secadas e montadas com verniz.

Todos os testes foram realizados com um controle reconhecidamente positivo e um negativo.

A análise do Ki-67 foi semiquantitativa com a reatividade e a localização da coloração celular graduada como 0 a 3+, de acordo com os critérios de Queiroz et al.(29): 0 . células positivas apenas nas camadas basal e parabasal; 1. proliferação < 20\%; 2. proliferação entre $21 \%$ e $40 \%$; 3. proliferação $>40 \%$.

A imunorreatividade para $\mathrm{Bax}$ e $\mathrm{BCl}-2$ foi semiquantitativa, apresentando os seguintes escores: 0 . sem marcação; 1 . fraco $<10 \%$; 2. $>10 \%$ e $<50 \%$; 3. $>50 \%$. A imunorreatividade foi considerada negativa quando houve escore 0 ou 1 e positiva quando houve escore de 2 ou 3, conforme os critérios de Oltvai et al.(26) e Joensuu et al. ${ }^{(16)}$. Além disso, os escores foram avaliados por dois patologistas, conforme indicado por Feng et al.(13).

Os parâmetros morfométricos foram submetidos ao teste de Kolmogorov-Smirnov para verificação de distribuição Gaussiana. Com essa distribuição, procedeu-se à análise de variância e à múltipla comparação de Student-Newman-Keuls. Sem ela, optou-se pelo teste não paramétrico de Kruskall-Wallis, acrescido do teste de múltiplas comparações de Dunn. Utilizou-se o programa Graphpad Prism 3.0. Médias e/ou medianas foram obtidas para cada parâmetro morfométrico.

\section{Resultados}

Os índices de apoptose obtidos na espessura total do epitélio e nas camadas superior e inferior deste foram crescentes ao longo do espectro das NICs a partir da categoria cervicite. Assim, a apoptose foi mínima na cervicite (4 \pm $0,25)$, menor na NIC $1(5,47 \pm 0,36)$, intermediária na NIC 2 $(7,56 \pm 0,47)$ e máxima na NIC $3(10,68 \pm 0,42)$ (Figura 1).

$\mathrm{Na}$ cervicite, a apoptose ocorreu de maneira pouco significativa, acometendo cerca de $4 \% \pm 0,25 \%$ das células. A maioria destas se localizou no extrato superior $(2,90 \% \pm$ $0,19 \%$ das células totais ou $\pm 75 \%$ das células em apoptose). Raras foram as células apoptóticas na camada inferior $(1,10 \% \pm 0,08 \%$ das células totais ou $\pm 25 \%$ das células em apoptose).

NIC 1 mostrou maiores índices apoptóticos $(5,47 \% \pm$ $0,36 \%)$ que a cervicite, com $p<0,01$. A maioria da apoptose se localizou no extrato superior $(3,10 \% \pm 0,31 \%$ das células totais ou $\pm 72 \%$ das células em apoptose). Menos frequentes foram as células apoptóticas na camada inferior $(1,60 \% \pm 0,19 \%$ das células totais ou $\pm 28 \%$ das células em apoptose).

NICs 2 e 3 apresentaram índices apoptóticos maiores $(7,56 \% \pm 0,47 \% ; 10,68 \% \pm 0,42 \%$, respectivamente) que cervicite e NIC 1, com $p<0,001$. A maioria da apoptose nas $\mathrm{NICs} 2$ e 3 se localizou no extrato superior $(5,72 \% \pm 0,40 \%$;

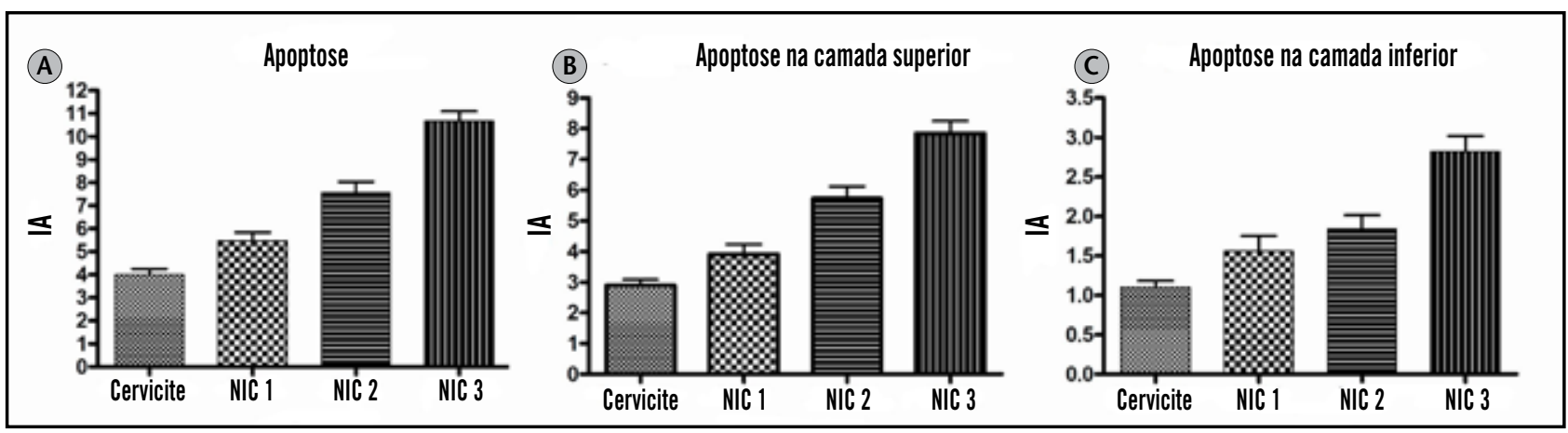

Figura 1 - Apoptose crescente ao longo do espectro das lesões intraepiteliais a partir da categoria cervicite crônica

(A) Total; (B) camada superior; (C) camada inferior.

IA: índice apoptótico; NIC: neoplasia intraepitelial cervical. 
$7,85 \% \pm 0,39 \%$ das células totais ou $75,66 \%$ e $73,50 \%$ das células em apoptose, respectivamente). Menos frequentes foram as células apoptóticas na camada inferior $(1,84 \% \pm$ $0,18 \% ; 2,83 \% \pm 0,19 \%$ das células totais ou $\pm 28,52 \%$ das células em apoptose).

A frequência das mitoses no epitélio cervical aumentou da cervicite para a NIC 3. Diferenças na distribuição das figuras de mitose entre NICs 1 e 2 foram observadas nas camadas superficiais do epitélio, vistas em NIC 2.

Mitoses ocorreram em todas as categorias (Figura 2A), porém foram raras, típicas e basais (Figura $\mathbf{2 C}$ ) nos grupos cervicite e NIC 1 e frequentes, por vezes atípicas e encontradas comumente nos extratos epiteliais médio e superior (Figura 2B), nas NICs 2 e 3.

Na análise quantitativa (não paramétrica), observaram-se baixos índices mitóticos na cervicite $(\mathrm{Md}=0,53)$ similares aos de NIC $1(\mathrm{Md}=0,66)$, $\operatorname{com} p>0,05$.

Por outro lado, as NICs 2 e 3 apresentaram índices mitóticos elevados, sendo a mediana de NIC 2 $(\mathrm{Md}=2,46)$ menor que a obtida para NIC $3(\mathrm{Md}=4,57)$, com $p<0,05$. Esses valores estão cerca de quatro a sete vezes mais elevados quando comparados em conjunto com a categoria cervicite/NIC 1 .

$\mathrm{Na}$ cervicite, células em interfase correspondiam à maioria, sendo $95,29 \% \pm 0,28 \%$ das células. Na NIC 1, correspondiam a $93,62 \% \pm 0,42 \%$, enquanto nas NICs 2 e 3 representaram, respectivamente, $89,62 \% \pm 0,54 \%$ e $84,24 \% \pm 0,56 \%$ das células (Figura 3).

Os resultados da imunomarcação para Ki-67 nos 80 cortes obtidos não tiveram distribuição normal nas três variáveis avaliadas (reatividade, localização e intensidade). Os resultados do teste de Kruskall-Wallis e de múltipla comparação de Dunn mostraram diferenças entre as medianas obtidas para os grupos NICs 1, 2 e 3.

Assim, a reatividade encontrada foi maior nas NICs 2 e $3(M d=2)$, quando em comparação com NIC 1 $(\mathrm{Md}=1)(p<0,001)$ (Figura 4A). Na localização das reações, o padrão de marcação foi semelhante entre os grupos $(\mathrm{Md}=1)$, embora os achados em NIC 1 tenham sido homogêneos e de menor dispersão que os em NICs 2 e 3 (Figura 4B).

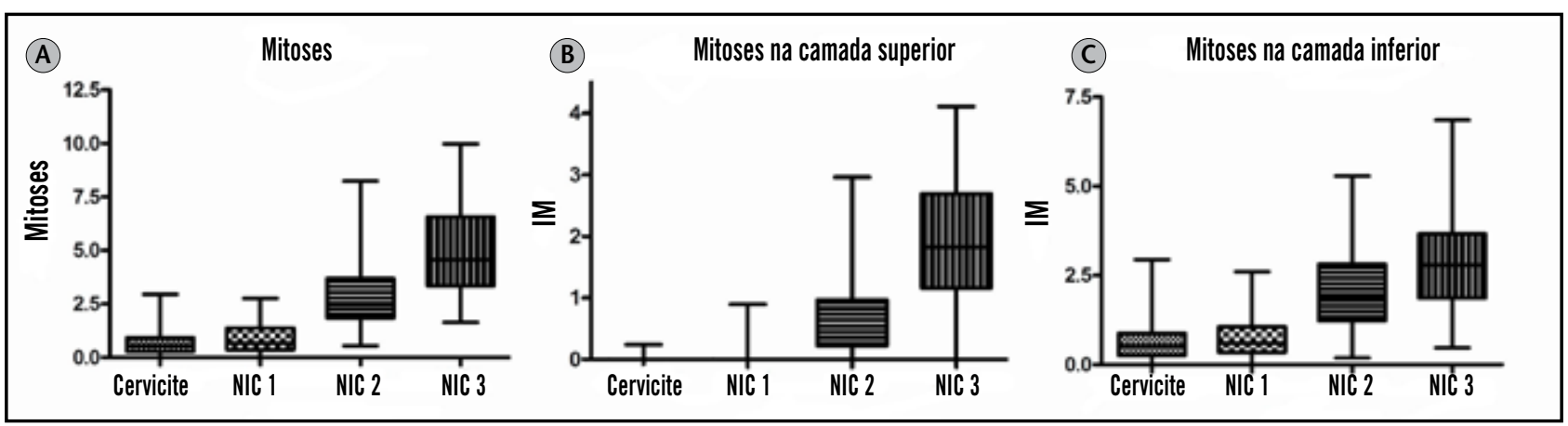

Figura 2 - Índice mitótico crescente ao longo do espectro das lesões intraepiteliais a partir da categoria cervicite (A) Índice mitótico total; $(B)$ índice mitótico na camada superior; $(C)$ índice mitótico na camada inferior. NIC: neoplasia intraepitelial cervical; IM: índice mitótico.

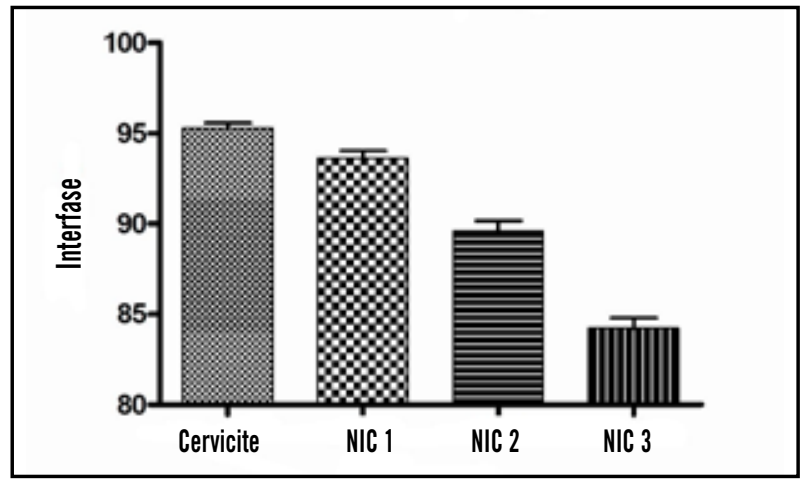

Figura 3 - Porcentagem decrescente de células em interfase ao longo do espectro das NICs a partir da categoria cervicite

NICs: neoplasias intraepiteliais cervicais.
A intensidade foi semelhante entre os grupos, tendo variado de moderada a acentuada (Figura 4C) (Figura 5).

Quanto à imunomarcação para $\mathrm{Bcl}-2$, processou-se a reação em 51 casos devido à exiguidade e ao desgaste apresentado por 29 blocos da amostragem. Destes, 15 foram cervicite; 13 , NIC 1; 11, NIC 2; 12 , NIC 3, o que resultou em 42 casos negativos (82,35\%) e nove positivos $(17,65 \%)$. Nos grupos cervicite e NIC 1, todos os casos foram negativos $(n=28)$. A imunomarcação para Bcl-2 foi positiva em nove dos 23 casos restantes, sendo $3 / 11$ casos em NIC 2 (27,27\%) e 6/12 casos em NIC 3 (50\%). Nos casos positivos $(n=9)$, a localização mostrou-se em células intermediárias em quatro $(44,44 \%)$ e cinco $(55,56 \%)$ em todo o epitélio (Figura 6). 


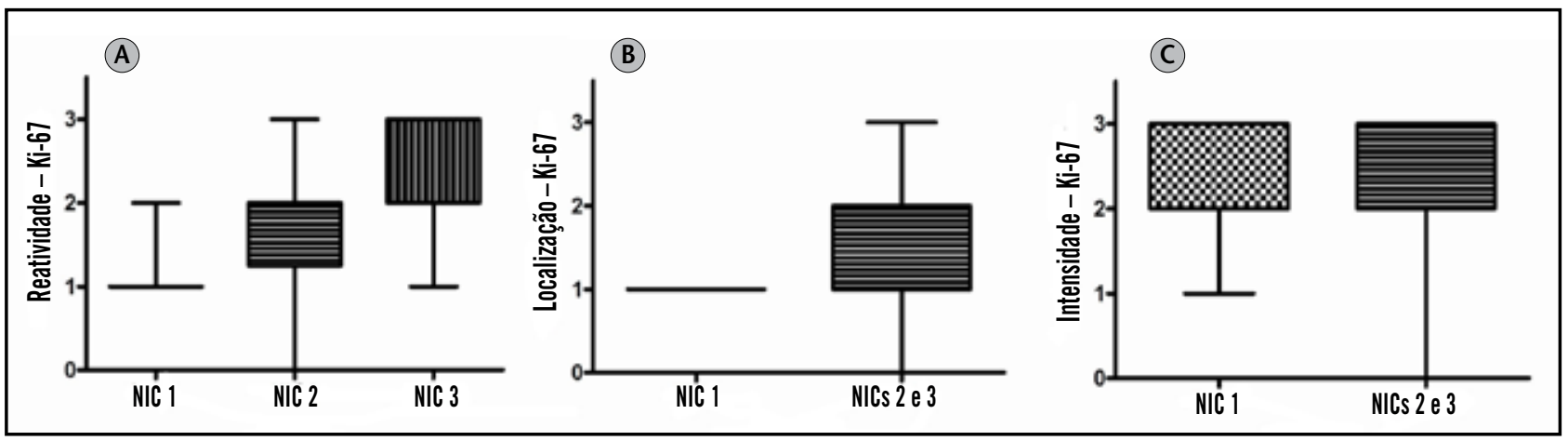

Figura 4 - Resultados da imunomarcação pelo Ki-67

(A) Reatividade: 1. <25\% de marcação; 2. entre 25\% e 50\% de marcação; 3. > 50\% de marcação; (B) localização: 1. na camada basal; 2. nas camadas basal e intermediária; 3. em todo o epitélio; (C) intensidade: 1. leve; 2. moderada; 3. acentuada.

NIC: neoplasia intraepitelial cervical.

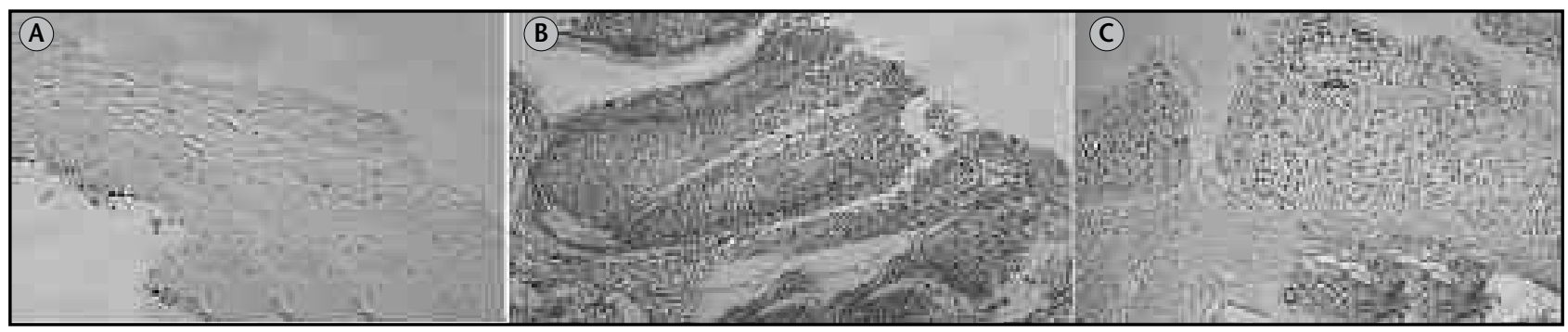

Figura 5 - Expressão da imunomarcação pelo Ki-67

(A) Cervicite crônica: reatividade baixa, intensidade fraca e localização nas células do extrato basal do epitélio escamoso; (B) NIC 2: reatividade acentuada, intensidade moderada e localização em toda a espessura epitelial; (C) NIC 3: reatividade acentuada, intensidade acentuada e localização em toda a espessura epitelial. Ki-67, 40x. NIC: neoplasia intraepitelial cervical.

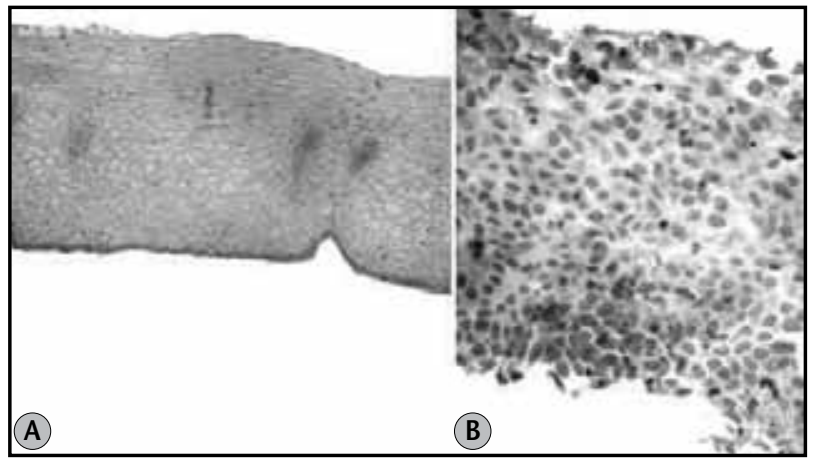

Figura 6 - Expressão da imunomarcação pelo Bcl-2

(A) Expressão de padrão basal encontrado na cervicite crônica. Bcl-2, 40x; (B) expressão em NIC 3, com detecção citoplasmática do antígeno. Bcl-2, 100x (contracoloração com hematoxilina).

NIC: neoplasia intraepitelial cervical.

Os resultados da reatividade, da localização e da intensidade da reação para Bax tiveram distribuição normal e foram analisados pelo teste de Mann-Whitney, por se tratar de variável ordinal. A reatividade da reação em NIC 1 $(M d=1)$ foi menor que nas NICs 2 e $3(M d=2)(p=0,0088)$

(Figura 7A). A localização da reação variou entre as NICs, com a média menor em NIC $1(\mathrm{Md}=2)$ e maior em NICs 2 e $3(\mathrm{Md}=2,5)$. Houve diferença estatisticamente significativa entre NICs 1 e 2 e entre NICs 1 e $3(p<0,05)$. Não houve diferença significativa entre NICs 2 e $3(p>0,05)$
(Figura 7B). A intensidade da reação em NIC $1(\mathrm{Md}=1)$ foi menor que nas lesões de alto grau, NICs 2 e $3(\mathrm{Md}=2)$ $(p=0,0015)$ (Figura 7C) (Figura 8).

\section{Discussão}

Os critérios morfológicos empregados para identificação e quantificação da apoptose foram os descritos por Kerr et al.(18). Esses critérios morfológicos foram validados com os resultados da imuno-histoquímica para Bax.

A apoptose foi mínima na cervicite, menor na NIC 1 , intermediária na NIC 2 e máxima na NIC 3, atingindo tanto na espessura total do epitélio quanto nas camadas superior e inferior. Assim, os índices obtidos foram crescentes ao longo do espectro das lesões intraepiteliais. No entanto, a distribuição da apoptose nas camadas superior e inferior do epitélio não mostrou grandes oscilações, mantendo a proporção.

A distribuição da apoptose obtida na morfometria para lesão intraepitelial de alto grau (LIE-AG) (NICs 2 e 3) é quase duas vezes superior que na LIE de baixo grau (LIE-BG) (NIC1) e na cervicite, o que está consistente com os resultados da imuno-histoquímica para Bax. 


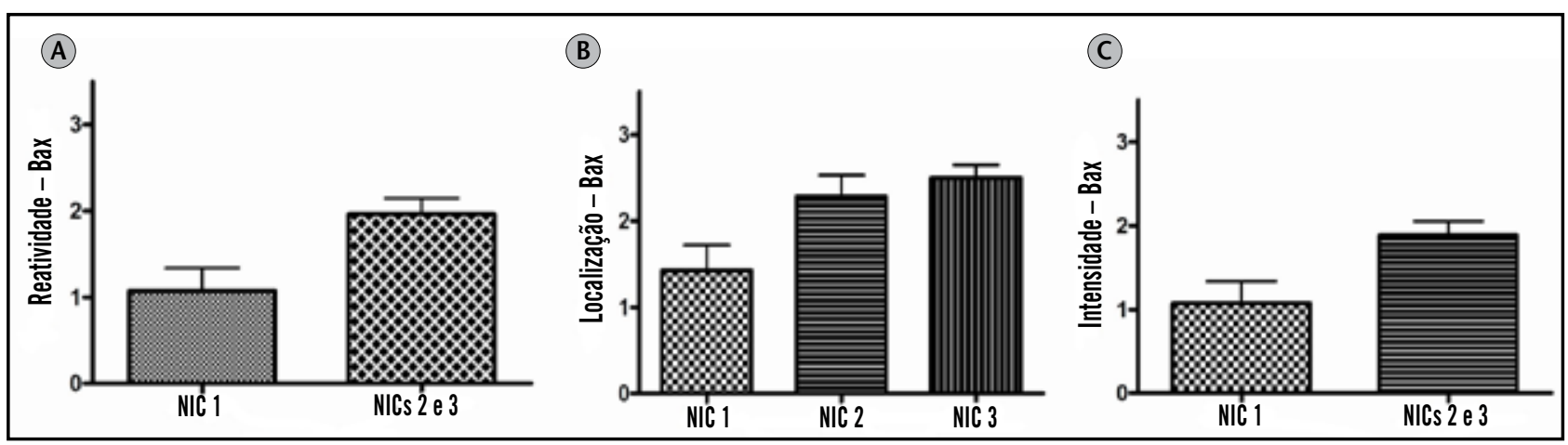

Figura 7 - Resultados da imunomarcação pelo Bax

(A) Reatividade: 1. < 25\% de marcação; 2. entre $25 \%$ e 50\% de marcação; 3. > 50\% de marcação; (B) localização: 1. na camada basal; 2. nas camadas basal e intermediária; 3. em todo o epitélio; (C) intensidade: 1. leve; 2. moderada; 3. acentuada.

NIC: neoplasia intraepitelial cervical.

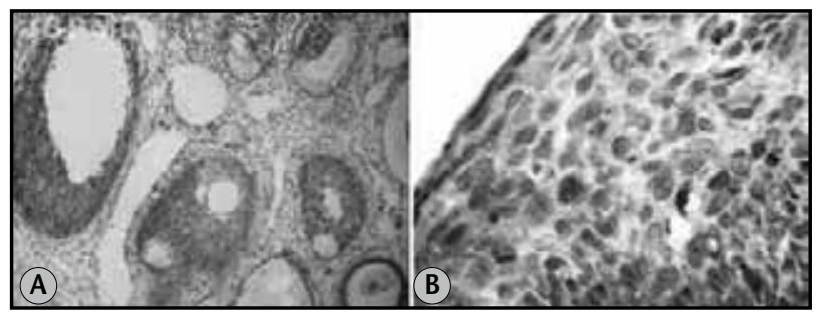

Figura 8 - Expressão da imunomarcação pelo Bax

(A) NIC 3: reatividade acentuada, intensidade acentuada e positividade em toda a espessura epitelial. Bax, 40x; (B) detalhe do padrão citoplasmático granular da reação. Bax, 100x (contracoloração com hematoxilina).

NIC: neoplasia intraepitelial cervical.

O aumento do índice apoptótico com o grau histológico sugere que a apoptose ajuda a eliminar células que se proliferaram em excesso, se desenvolveram impropriamente ou que mantiveram dano genético ${ }^{(8,34)}$. A identificação da apoptose aumentada em processos pré-neoplásicos para lesões neoplásicas foi observada em outros tumores epiteliais humanos ${ }^{(1,4)}$. Claramente, o controle da população celular em epitélio em diferenciação é complexo e envolve a diferenciação e a apoptose.

O índice mitótico é importante na análise da taxa de crescimento, entretanto, reflete apenas uma das variáveis em estudo do crescimento dessas lesões ${ }^{(12)}$. O número de mitoses, típicas e atípicas, e sua localização são utilizados para graduar as lesões ${ }^{(32,33)}$. Em nosso estudo, as mitoses ocorreram em todas as categorias, porém foram raras, típicas e basais nos grupos cervicite e NIC 1 e frequentes, por vezes atípicas e localizadas nos extratos epiteliais médio $\mathrm{e}$ superior, nas LIE-AGs (NICs 2 e 3). Na cervicite, as figuras de mitose são raramente encontradas; quando presentes, elas estão confinadas às camadas basais e não mostram atipias. Nas neoplasias intraepiteliais, as mitoses ocorrem com maior frequência nas camadas suprabasais e podem ser atípicas ${ }^{(33)}$. Os baixos índices mitóticos na cervicite e na
NIC 1 contrastaram com os obtidos para NICs 2 e 3, sendo quatro a sete vezes mais elevados quando comparados em conjunto. Essas observações indicam que as mitoses no epitélio possuem relação com o grau da $\mathrm{NIC}{ }^{(11)}$. A ocorrência de eventos nulos nas cervicites e NIC 1, esperada pelos critérios de classificação das LIEs, dificultaram a avaliação estatística, comprometendo maiores inferências.

A avaliação combinada de apoptose, mitose e em estado não replicativo indica que as LIE-AGs possuem maior grau de renovação celular que a cervicite e a NIC 1. Tanto a proliferação quanto a apoptose aumentaram com o grau da lesão, reduzindo a fração de células em interfase. A porcentagem de células em proliferação e apoptose na cérvice normal difere significativamente em todas as lesões displásicas. Nas LIE-AGs, observa-se imortalização celular, com proliferação celular anárquica e autônoma, elevando o índice mitótico ${ }^{(13)}$. Por outro lado, a resposta do hospedeiro diante da displasia se traduz em aumento da apoptose ${ }^{(11)}$.

Nas LIE-BGs, a proliferação não está associada à apoptose mensurável. Essas lesões ainda retêm a capacidade de diferenciação escamosa, com controle da celularidade. Com o aumento do grau histológico, a diferenciação é reduzida ou perdida, mas níveis mensuráveis de apoptose são identificados ${ }^{(11,34)}$.

Na reatividade da imuno-histoquímica para Ki-67, os níveis crescentes de células marcadas têm relação com o grau da displasia e o índice mitótico. Essa correlação positiva é descrita entre o grau da NIC e a proliferação nuclear ${ }^{(21)}$. Na cervicite, a reatividade foi mínima ou nula. Constatou-se diferença significativa entre NICs 1 e 2 e entre NICs 1 e 3. Entretanto, não houve diferença na comparação entre NICs 2 e 3. As LIE-AGs mostraram índices mitóticos elevados em comparação com os grupos cervicite e NIC 1, em 
consonância com a morfometria. Nas NICs 2 e 3, os índices do Ki-67 foram moderado e acentuado, respectivamente, e divergem, em contrapartida, de NIC 1, que possui índices menores (baixo/moderado). Níveis elevados como esses são mais observados em tumores malignos com elevada proliferação ${ }^{(20)}$. A frequência e a distribuição da marcação do Ki-67 podem também distinguir cervicite das $\mathrm{NICs}^{(10)}$. $\mathrm{Na} \mathrm{NIC} 3$, a fração de células Ki-67 positivas fica em torno de $40 \%$, sendo duas a cinco vezes maior que em NIC 1. Frações excedendo $25 \%$ são exclusivamente encontradas nas NICs 2 e $3^{(13)}$.

A expressão do Ki-67 apresenta relação com a progressão da displasia para alto grau ${ }^{(29)}$. O Ki-67 é útil para identificar LIE-BG e na verificação de diagnósticos equívocos ${ }^{(35)}$. Portanto, para efeitos diagnósticos, infere-se que a variável reatividade pode ajudar no esclarecimento de lesões em que paira dúvida da presença ou não de displasia e se a lesão é de baixo ou alto grau.

No cervicite, a marcação para Ki-67 foi encontrada nas células parabasais e basais, constatando que as células parabasais são fontes de renovação celular e que as basais funcionam como células de reserva ${ }^{(27,36)}$.

Mimica et al. ${ }^{(25)}$ e Popiolek et al. ${ }^{(28)}$ constataram expressão aumentada do Ki-67 na coilocitose e na NIC, progressivamente maior nas camadas altas do epitélio, de acordo com o grau da displasia. No presente estudo, a maior marcação em NIC 1 foi no terço médio do epitélio, enquanto nas NICs 2 e 3 foi no terço superior ou em todo o epitélio. Lorenzato et al. (24) relataram células Ki-67 positivas nos dois terços superiores do epitélio como um método acurado para detectar LIE-AGs com sensibilidade de 100\%. Mimica et al. ${ }^{(25)}$ e Popiolek et al. ${ }^{(28)}$ também mostraram que Ki-67 melhora a sensibilidade do diagnóstico das lesões de alto grau. Assim, a localização das células em proliferação possui correlação com o grau histomorfológico das displasias ${ }^{(28)}$. As células Ki-67 positivas aumentam progressivamente no interior do epitélio à medida que se eleva o grau lesional. Nas lesões intraepiteliais, a expressão de Ki-67 aumenta nas áreas parabasais com extensão nas camadas intermediárias e superficiais ${ }^{(36)}$.

Portanto, a variável localização na imuno-histoquímica para Ki-67 é um recurso útil para dicotomizar as LIEs (28), com repercussões práticas no prognóstico/evolução da lesão. Para Baak et al. ${ }^{(3)}$ e Kruse et al. ${ }^{(19)}$, o antígeno Ki-67 prediz a progressão nas lesões intraepiteliais graus 1 e 2 . A imuno-histoquímica para Ki-67 tem potencial na graduação da NIC e na distinção com as lesões não neoplásicas que as mimetizam. A positividade para o Ki-67 está associada à detecção do HPV, tanto em lesões cervicais quanto vulvares, com elevada sensibilidade e especificidade ${ }^{(17,22)}$.

Quanto à variável intensidade, não se observou diferença entre os grupos das displasias. Isso demonstra que a intensidade da reação pelo Ki-67 se presta para esclarecimento diagnóstico nas lesões em que há dúvida quanto à presença de displasia, notadamente entre displasia leve e cervicite (atipias celulares inflamatórias).

A expressão de Ki-67 pode ser um método diagnóstico nos casos difíceis, em que o epitélio atrófico e reativo deve ser diferenciado de displasia e carcinoma invasivo ${ }^{(13,19)}$.

Quanto à imunorreatividade pelo Bax, o padrão granular é detectado nas displasias em confronto com a cervicite ${ }^{(14)}$. Nossos resultados mostram que não houve diferença entre as displasias no que se refere à reatividade, similar ao relatado por Aletra et al. ${ }^{(2)}$. O que se notou foi a diferença entre cervicite e NICs 2 e 3, sustentada pela avaliação morfométrica do índice apoptótico, visto que não se encontrou apoptose significativa na primeira categoria. Não houve diferença entre cervicite e NIC 1 e esse parâmetro apenas dicotomiza a cervicite das LIE-AGs.

Quanto à localização da reação com Bax, os resultados indicam diferença significativa entre LIE-BG e LIE-AG. Dessa forma, na neoplasia intraepitelial, células Bax positivas aumentam progressivamente no epitélio à medida que se aumenta o grau lesional. $\mathrm{O}$ aumento da apoptose é devido ao crescente acúmulo de dano genético nas células displásicas ${ }^{(8)}$. Portanto, a variável localização para Bax é útil para diferenciar lesões de baixo e alto graus, o que demonstra importância prática nos casos duvidosos à histologia.

Quanto à variável intensidade com Bax, nossos resultados mostraram diferença significativa entre LIE-AG e LIE-BG. Quando analisamos NICs 2 e 3 como grupo (LIE-AG) e confrontamos com NIC 1, observamos diferença significativa. Assim, as LIE-BGs apresentam intensidade leve, enquanto as LIE-AGs, intensidade moderada. Esses achados indicam que as LIE-AGs são semelhantes entre si no que se refere à apoptose e que divergem das LIE-BGs e da cervicite. A literatura reforça esse $\operatorname{achado}^{(7,14)}$.

A expressão do Bcl-2 nos grupos cervicite e NIC 1 ocorreu nas células do extrato parabasal, concordando com estudos de Cheah e Meng ${ }^{(7)}$. Essa expressão reflete a função germinativa desse compartimento. Aparentemente, $\mathrm{BCl}$-2 é requerido para a sobrevivência dessas células germinativas, a fim de que se mantenha a homeostasia epitelial. Adicionalmente, as LIE-AGs mostraram aumento progressivo de $\mathrm{BCl}-2$, concordando com Looi et al. ${ }^{(23)}$ e Cheah e Meng ${ }^{(7)}$. 
A progressão tumoral está associada ao equilíbrio entre a proliferação celular e a apoptose. Membros da família gênica que incluem Bcl-2 e Bax estão envolvidos no controle da apoptose de extensa variedade de tipos celulares. Bax induz a apoptose e $\mathrm{Bcl}-2$ atua na sobrevivência celular. $\mathrm{O}$ $\mathrm{BCl}-2$ e outros membros da família competem para inativar o $\mathrm{Bax}^{(30)}$. O prolongamento da sobrevivência celular e a inibição da apoptose está relacionado com a carcinogênese ${ }^{(14)}$. Todavia, a redução da expressão do $\mathrm{BCl}-2$ não necessariamente traduz um aumento da apoptose, porque outros fatores podem estar alterados ${ }^{(8,13)}$. Dessa forma, não há necessariamente uma correlação de $\mathrm{Bcl}-2$ com Bax ${ }^{(14)}$.

As duas abordagens empregadas em nosso estudo, histomorfometria e imuno-histoquímica, avaliam o mesmo processo patológico, porém com níveis de resolução diferentes. A histomorfometria constata alterações no plano de resolução tissular, sendo que as alterações morfológicas são observadas e quantificadas à microscopia óptica. A imuno-histoquímica, por conseguinte, constata alterações no plano da expressão, de forma mais precoce que o dano celular e tissular, sustentando os resultados vistos à microscopia óptica.

A partir das duas abordagens, constatou-se a ocorrência de apoptose e mitose nas displasias e ambas estão diretamente relacionadas com o aumento do grau de displasia. O evento displásico é dinâmico e representa um processo patológico com níveis crescentes de renovação celular, também proporcional ao grau de displasia.

Os resultados das duas abordagens, de naturezas diferentes (quantitativa e semiquantitativa), enfocam, em essência, os mesmos processos e apresentam pequena discrepância entre os índices morfométricos e de marcação imuno-histoquímica. Entretanto, por uma perspectiva mais ampla, os resultados da morfometria são sustentados pela imuno-histoquímica. Assim, os índices apoptótico e mitótico mostram o mesmo padrão de resposta que a marcação imuno-histoquímica para $\mathrm{Bax}, \mathrm{BCl}-2$ e $\mathrm{Ki}-67$, sendo que a imuno-histoquímica é capaz de captar alterações celulares mais precocemente.

Além disso, é importante ressaltar que os níveis de expressão do Ki-67 nem sempre encontram paralelismo com os do $\mathrm{BCl}-2$, o que indica que a atividade proliferativa e a apoptose são fatores independentes para a manutenção da displasia. Nos casos em que ambos os marcadores são intensamente expressos, a proteção contra a morte celular via apoptose possui efeito sinérgico na acumulação de células displásicas.

\section{Conclusão}

Os resultados apresentados sustentam a teoria de que a NIC envolve progressiva disfunção da renovação cervical (proliferação e morte celular) e suportam as seguintes inferências:

- os marcadores Ki-67, Bax e Bcl-2, em combinação com a análise de imagens, oferecem uma alternativa promissora para a classificação das displasias cervicais;

- a histomorfometria e a imuno-histoquímica, apesar de envolverem análises diferentes (quantitativa e semiquantitativa), enfocam, em essência, os mesmos processos que, vistos por uma perspectiva mais ampla, mostram resultados similares. Assim, os índices apoptótico e mitótico apresentam o mesmo padrão de resposta que a marcação imuno-histoquímica para Bax, Bcl-2 e Ki-67;

- as células em interfase decrescem ao longo do espectro das lesões intraepiteliais a partir da categoria cervicite;

- a imuno-histoquímica para Ki-67, Bax e Bcl-2 é importante no estudo das lesões do colo uterino, proporcionando diagnóstico mais preciso, especialmente nas lesões duvidosas à histologia;

- os parâmetros reatividade, localização e intensidade da reação para Ki-67 são úteis na avaliação da presença de displasia. Na presença desta, apenas os parâmetros reatividade e localização são capazes de diferenciar lesões de baixo e alto grau;

- os parâmetros localização e intensidade para Bax são capazes de diferenciar lesões de baixo e alto grau; já a reatividade é capaz de dicotomizar lesões de alto grau com cervicite;

- a expressão do Bcl-2 eleva-se com a gravidade da displasia. 


\section{Referências}

1. AlHARA, M. et al. Frequency of apoptotic bodies positively correlates with Gleason grade in prostate cancer. Hum Pathol, v. 25, p. 797-801, 1994.

2. ALETRA, C. et al. Expression of bcl-2 and bax in cervical intraepithelial neoplasia and invasive squamous cell carcinoma of the uterine cervix. Eur J Gynaecol Oncol, v. 21 , n. 5, p. 494-8, 2000.

3. BAAK, J. P. A. et al. Predictive testing of early CIN behavior by molecular biomarkers. Cellular Oncology, n. 27, p. 277-80, 2005.

4. BERGES, R. R. et al. Implications of cell kinetic changes during the progression of human prostatic cancer. Clin Cancer Res, v. 1, p. 473-80, 1995.

5. BRASIL. Ministério da Saúde. Instituto Nacional de Câncer. Estimativa 2010: incidência de câncer no Brasill Instituto Nacional de Câncer. Rio de Janeiro: INCA, 2009. 98 p.

6. CASTLE, P. E. et al. Human papillomavirus type 16 infections and 2 year absolute risk of cervical precancer in women with equivocal or mild cytologic abnormalities. J Natl Cancer Inst, v. 97, p. 1066-71, 2005.

7. CHEAH, P.; MENG, L. Significance of Bcl-2 and Bax proteins in cervical carcinogenesis: an immunohistochemical study in squamous cell carcinoma and squamous intraepithelial lesions. Malaysian J Pathol, v. 28, p. 1-5, 2006.

8. CHEUNG, T. K. et al. Apoptosis-related proteins in cervical intraepithelial neoplasia and squamous cell carcinoma of the cervix. Gynecol Oncol, v. 86, p. 14-8, 2002.

9. COGLIANO, V. et al. WHO International Agency for Research on Cancer. Carcinogenicity of human papillomaviruses. Lancet Oncol, v. 6, p. 204, 2005.

10. CRUM, C. P. Contemporary theories of cervical carcinogenesis: the virus, the host, and the stem cell. Mod Pathol, v. 13, n. 3, p. 243-51, 2000.

11. DEY, P.; DAS, R.; SABUDDIN. Correlations between apoptotic and proliferative indices in cervical intraepithelial neoplasia and carcinoma. Indian J Pathol Microbiol, v. 43, n. 3, p. 271-5, 2000.

12. FELIX, W.; WONG, S. Immunohistochemical detection of proliferating tumor cells in cervical cancer using monoclonal antibody Ki-67. Gynecol Obstet Invest, v. 37 p. 123-6, 1994.

13. FENG, W. et al. Senescence and apoptosis in carcinogenesis of cervical squamous carcinoma. Modern Pathology, v. 20, p. 961-6, 2007.

14. GIARNIERI, E. et al. Msh2, Mib1, Fhit, p53, Bcl-2, and Bax expression in invasive and in situ squamous cell carcinoma of the uterine cervix. Clinical Cancer Research, v. 6, n. 3600, p. 3600-6, 2000.

15. GIRALDO, P. C. et al. Neoplasia intra-epitelial cervical: estudo de p16 como fator prognóstico e suas correlações com p53 e MIB-1 em lesões de baixo grau positivas. Newslab, v. 78, p. 100-9, 2006.

16. JOENSUU, N. et al. Bcl-2 protein expression and long term survival in breast cancer. Am J Pathol, v. 145, p. 1191-8, 1994.
17. KALOF, A. N.; COOPER, K. Our approach to squamous intraepithelial lesions of the uterine cervix. J Clin Pathol, v. 60, p. 449-55, 2007.

18. KERR, J. F. R. et al. Apoptosis: a basic biologic phenomenon with wide ranging applications in tissue kinetics. Brit J Cancer, v. 26, p. 239, 1972.

19. KRUSE, A. J. et al. Ki67 predicts progression in early CIN: validation of a multivariate progression-risk model. Cell Oncol, v. 26, n. 1-2, p. 13-20, 2004.

20. KUENEN-BOUMEESTER, V. et al. Ki-67 staining in histological subtypes of breast carcinoma and fine needle aspiration smears. J Clin Pathol, v. 44, p. 208-10, 1991.

21. LEE, J. S. et al. Angiogenesis, cell proliferation and apoptosis in progression of cervical neoplasia. Anal Quant Cytol Histol, v. 24, n. 2, p. 103-13, 2002.

22. LOGANI, S. et al. Low grade vulvar and vaginal intraepithelial neoplasia: correlation of morphologic features with Mib-1 immunostaining and HPV DNA detection. [Abstract 814]. Mod Pathol, v. 14, p. A139, 2001.

23. LOOI, M. L. et al. Expression of p53, bcl-2 and ki-67 in cervical intraepithelial neoplasia and invasive squamous cell carcinoma of the uterine cervix. Anal Quant Cytol Histol, v. 30, n. 2, p. 63-70, 2008.

24. LORENZATO, M. et al. Cell cycle and/or proliferation markers: what is the best method to discriminate cervical high-grade lesions? Hum Pathol, v. 36, n. 10, p. 1101-7, 2005.

25. MIMICA, M. et al. Ki-67 quantitative evaluation as a marker of cervical intraepithelial neoplasia and human papillomavirus infection. Int J Gynecol Cancer, v. 20, n. 1, p. 116-9, 2010.

26. OLTVAI, Z. et al. Bcl-2 heterodimerizes in vivo with a conserved homologue, BAX, that accelerates programmed cell death. Cell, v. 74, p. 609-19, 1993.

27. PIROG, M. D. et al. Diagnostic accuracy of cervical low grade squamous intraepithelial lesions is improved with Mib-1 immunostaining. Am J Surg Pathol, v. 26, n. 1, p. 70-5, 2002

28. POPIOLEK, D.; VENTURA, K.; MITTAL, K. Distinction of low-grade squamous intraepithelial lesions from high-grade squamous intraepithelial lesions based on quantitative analysis of proliferative activity. Oncol Rep, v. 11, n. 3, p. 687-91, 2004.

29. QUEIROZ, C. et al. Comparative study of the expression of cellular cycle proteins in cervical intraepithelial lesions. Pathology: research and practice, v. 202, p. 731-7, 2006.

30. SEDLACK, T. et al. Multiple bcl-2 family members demonstrate selective dimerization with bax. Proc Natl Acad Sci USA, v. 92, p. 7834-8, 1995.

31. SOSLOW, R. A.; ISACSON, C.; ZALOUDEK, C. Immunohistology of the female genital tract. In: DABBS, D. J. Diagnostic immunohistochemistry. 2. ed. Pittsburg: Elsevier, 2006. cap.16, p. 637-745.

32. STEINBECK, R. G. Dysplasia in view of the cell cycle. Eur J Histochem, v. 48, n. 3, p. 203-11, 2004. 
33. VAN LEEUWEN, A. M. et al. Atypical mitotic figures and the mitotic index in cervical intraepithelial neoplasia. Virchows Arch, v. 427, n. 2, p. 139-44, 1995.

34. WALKER, F. et al. Increased apoptosis in cervical intraepithelial neoplasia associated with HIV infection: implication of oncogenic human papillomavirus, caspases, and Langerhans cells. Clin Cancer Res, v. 11, n. 7, p. 2451-8, 2005.

35. XUE, Y. et al. Proliferative activity in cervical intraepithelial neoplasia and cervical carcinoma. Chin Med J, v. 112, n. 4, p. 373-5, 1999.
36. ZANOTTI, S.; FISSELER-ECKHOFF, A.; MANNHERZ, H. G. Changes in the topological expression of markers of differentiation and apoptosis in defined stages of human cervical dysplasia and carcinoma. Gynecol Oncol, v. 89, n. 3, p. 376-84, 2003.

37. ZUNA, E. R. et al. Comparison of human papillomavirus genotypes in high-grade squamous intraepithelial lesions and invasive cervical carcinoma: evidence for differences in biologic potential of precursor lesions. Mod Pathol, v. 17, p. 1314-22, 2004. 